\title{
Microdistribution of Magnetic Resonance Imaging Contrast Agents in Atherosclerotic Plaques Determined by LA-ICP-MS and SR- $\mu$ XRF Imaging
}

\author{
Yavuz Oguz Uca $\odot,{ }^{1}$ David Hallmann, ${ }^{2}$ Bernhard Hesse, ${ }^{3,4}$ Christian Seim, ${ }^{3,5}$ \\ Nicola Stolzenburg, ${ }^{1}$ Hubertus Pietsch, ${ }^{2}$ Jörg Schnorr, ${ }^{1}$ Matthias Taupitz ${ }^{1}$ \\ ${ }^{1}$ Charité - Universitätsmedizin Berlin, corporate member of Freie Universität Berlin, Humboldt-Universität zu Berlin, and Berlin Institute of \\ Health, Charitéplatz 1, 10117, Berlin, Germany \\ ${ }^{2} \mathrm{MR}$ and $C T$ Contrast Media Research, Bayer AG, Berlin, Germany \\ ${ }^{3}$ Xploraytion GmbH, Berlin, Germany \\ ${ }^{4}$ European Synchrotron Radiation Facility (ESRF), Grenoble, France \\ ${ }^{5}$ Technische Universität Berlin, Berlin, Germany
}

\begin{abstract}
Purpose: Contrast-enhanced magnetic resonance imaging (MRI) has the potential to replace angiographic evaluation of atherosclerosis. While studies have investigated contrast agent (CA) uptake in atherosclerotic plaques, exact CA spatial distribution on a microscale is elusive. The purpose of this study was to investigate the microdistribution of gadolinium (Gd)- and iron ( $\mathrm{Fe})$ oxide-based CA in atherosclerotic plaques of New Zealand White rabbits.

Procedures: The study was performed as a post hoc analysis of archived tissue specimens obtained in a previous in vivo MRI study conducted to investigate signal changes induced by very small superparamagnetic iron oxide nanoparticles (VSOP) and Gd-BOPTA. For analytical discrimination from endogenous $\mathrm{Fe}$, VSOP were doped with europium $(\mathrm{Eu})$ resulting in EuVSOP. Formalin-fixed arterial specimens were cut into $5-\mu \mathrm{m}$ serial sections and analyzed by immunohistochemistry (IHC: Movat's pentachrome, von Kossa, and Alcian blue ( $\mathrm{pH} 1.0)$ staining, anti-smooth muscle cell actin (anti-SMA), and anti-rabbit macrophage (anti-RAM-11) immunostaining) and elemental microscopy with laser ablation inductively coupled plasma mass spectrometry (LA-ICP-MS) and synchrotron radiation $\mu$ X-ray fluorescence (SR- $\mu \mathrm{XRF}$ ) spectroscopy. Elemental distribution maps of $\mathrm{Fe}, \mathrm{Eu}, \mathrm{Gd}$, sulfur (S), phosphorus (P), and calcium (Ca) were investigated.

Results: IHC characterized atherosclerotic plaque pathomorphology. Elemental microscopy showed $S$ distribution to match the anatomy of arterial vessel wall layers, while $P$ distribution corresponded well with cellular areas. LA-ICP-MS revealed Gd and Fe with a limit of detection of $\sim 0.1 \mathrm{nmol} / \mathrm{g}$ and $\sim 100 \mathrm{nmol} / \mathrm{g}$, respectively. Eu-positive signal identified VSOP presence in the vessel wall and allowed the comparison of Eu-VSOP and endogenous Fe distribution in tissue sections. Extracellular matrix material correlated with Eu signal intensity, Fe concentration, and
\end{abstract}


maximum Gd concentration. Eu-VSOP were confined to endothelium in early lesions but accumulated in cellular areas in advanced plaques. Gd distribution was homogeneous in healthy arteries but inhomogeneous in early and advanced plaques. SR- $\mu$ XRF scans at $0.5 \mu \mathrm{m}$ resolution revealed $\mathrm{Gd}$ hotspots with increased $\mathrm{P}$ and $\mathrm{Ca}$ concentrations at the intimomedial interface, and a size distribution ranging from a few micrometers to submicrometers.

Conclusions: Eu-VSOP and Gd have distinct spatial distributions in atherosclerotic plaques. While Eu-VSOP distribution is more cell-associated and might be used to monitor atherosclerotic plaque progression, Gd distribution indicates arterial calcification and might help in characterizing plaque vulnerability.

Keywords: Atherosclerosis, MRI, Gadolinium, Iron oxide nanoparticles, Elemental microscopy, LA-ICP-MS, SXRFS, Extracellular matrix, Arterial calcification

\section{Introduction}

Atherosclerosis is the major promoter of cardiovascular disease with clinical manifestations including myocardial infarction, ischemic stroke, and sudden death [1]. In clinical routine, arterial stenosis or occlusion is diagnosed by X-ray angiography, computed tomography (CT) angiography (CTA), magnetic resonance imaging (MRI) angiography (MRA), or color-coded sonography (CCS). However, discrimination between stable and vulnerable atherosclerotic plaques is not reliably possible. Smaller plaques, which are not detected by these imaging modalities, can be subject to inflammation-driven complications that might result in fissures or erosions with the risk of thrombotic vessel wall occlusion [2].

Imaging methods including MRI, CT, positron emission tomography (PET), catheter-based virtual histology intravascular ultrasound (VH-IVUS), optical coherence tomography (OCT), and near-infrared spectroscopy (NIRS) are currently being investigated regarding their value for characterizing morphological changes leading to vulnerable plaque [3-7]. Among these methods, contrast-enhanced MRI allows noninvasive angiographic examination and assessment of local plaque composition [8]. Dynamic MRI acquisition after intravenous (IV) injection of contrast agents (CA) offers quantitative characterization of inflammatory processes during plaque progression. Several types of CA have been investigated for these purposes: (I) iron oxide nanoparticles (IONP), which are currently available only for experimental use, and (II) clinically available lowmolecular-weight gadolinium (Gd)-based chelates (GBCA).

IONP are extensively used in MR imaging of experimental atherosclerosis particularly for detection of angiogenesis, inflammation, and apoptosis [9, 10]. IONP can be conjugated to antibodies or peptides to serve for targeted visualization of endothelial activity or myocardial infarction $[11,12]$. After IV injection, IONP are rapidly cleared by the reticuloendothelial system due to their relatively large size. This provides a unique strategy for contrast-enhanced MRI, since phagocytosis results in concentration of the nanoparticles, which becomes detectable as decreased signal intensity typically $24 \mathrm{~h}$ after IV injection [13, 14]. Studies investigating very small superparamagnetic iron oxide nanoparticles (VSOP) with a hydrodynamic diameter of $7 \mathrm{~nm}$, longer blood half-life, and faster vascular distribution due to their citrate surface coating have demonstrated even earlier uptake $(<2 \mathrm{~h})$ into the atherosclerotic plaques, which correlated with the accumulation of extracellular matrix (ECM) $[15,16]$.

GBCA are known as nonspecific agents that result in increased MRI signal intensity through pronounced perfusion and vascular permeability. Although GBCA were developed to distribute within the vascular and extracellular space, and to be eliminated as intact molecules via the kidneys, studies have demonstrated $\mathrm{Gd}$ deposition predominantly around vascularized areas of the skin, brain, liver, and kidney [17, 18]. Systemic metal deposition was proposed, and colocalization of elements including phosphorus $(\mathrm{P})$ or calcium (Ca) has suggested transchelation of $\mathrm{Gd}$ by physiological anions [19-21]. Although Gd deposition in the heart and aorta has also been reported, quantitative research in atherosclerotic plaques remains inadequate [19].

Discrimination between stable and vulnerable atherosclerotic plaques by contrast-enhanced MRI entails better understanding of IONP or GBCA interactions with plaque ECM components. Thus, elucidating microdistribution of $\mathrm{CA}$ in atherosclerotic plaques at different stages of disease progression by an experimental workflow with improved tissue detection ability offers a sophisticated basis. In this regard, mass spectrometry and X-ray fluorescence (XRF) analysis have emerged as two cutting-edge elemental microscopy techniques offering the lowest limit of detection (LOD) for reliable quantification of elements in tissue specimens and imaging characterization at the highest spatial resolution, respectively $[22,23]$.

In this study, we aimed to investigate the microdistribution of Eu-VSOP and Gd-BOPTA (gadobenate dimeglumine) in atherosclerotic plaques of New Zealand White (NZW) rabbits using immunohistochemistry (IHC) and elemental microscopy by laser ablation inductively coupled plasma mass spectrometry (LA-ICP-MS), and synchrotron radiation $\mu$ XRF (SR$\mu \mathrm{XRF}$ ) spectroscopy. 


\section{Materials and Methods}

\section{Animal Procedures}

The study was conducted in accordance with the requirements of directive 2010/63/EU and the German Animal Protection Act and approved by the local animal protection committee of the Landesamt für Gesundheit und Soziales (LAGeSo, Berlin State Office for Health and Social Affairs, Germany). Experimental conditions were constant at all times (see electronic supplementary material for induction of atherosclerosis). Twelve male NZW rabbits were IV injected with VSOP at a dose of $0.05 \mathrm{mmol} \mathrm{Fe} / \mathrm{kg}$ body weight. VSOP were synthesized at the Charité Department of Radiology according to the protocol described by de Schellenberger et al. and had the following properties: $0.5 \mathrm{M} \mathrm{Fe}$ concentration with $13 \%$ citric acid (weight/weight total $\mathrm{Fe}), 3 \mathrm{~g} / 1$ sodium glycerophosphate, $2 \mathrm{~g} / 1 \mathrm{~N}-$ methylglucamine, and $60 \mathrm{~g} / \mathrm{l}$ mannitol [24]. Synthesis was adapted to yield the final pharmaceutical formulation of the investigational drug VSOP-C184 used in clinical trials [25]. For unambiguous analytical discrimination from endogenous $\mathrm{Fe}$, VSOP were doped with europium (Eu) by substituting ferric ions in a $5 \%$ weight ratio of $\mathrm{Eu} 3+$ to $\mathrm{Fe} 3+$ resulting in Eu-VSOP, which has no influence on the magnetic properties of the particles [26]. At $1 \mathrm{~h}$ after Eu-VSOP injection, 10 rabbits were IV injected with Gd-BOPTA (Bracco Imaging Deutschland GmbH, Konstanz, Germany) at a dose of $0.1 \mathrm{mmol} / \mathrm{kg}$, since Gd-BOPTA was often preferred for vascular MRI. The rabbits were sacrificed $2 \mathrm{~h}$ after the initial CA administration. The vascular system was perfused with electrolyte solution and the aortic arch was removed and processed by formalin fixation at $4{ }^{\circ} \mathrm{C}$ overnight and embedded in paraffin. Atherosclerosis-free control specimens (Eu-VSOP-negative and Gd-positive controls were Vasovist and elastin-specific CA (BMS753951) administered at a dose of $0.2 \mathrm{mmol} / \mathrm{kg}$ ) were kindly provided by Marcus Makowski from our institution and processed under the same conditions [27].

\section{Immunohistochemistry}

The paraffin blocks were cut into 5 - $\mu \mathrm{m}$ serial sections using an automated microtome, which were mounted on SuperFrost Ultra Plus microscope slides (VWR International, Geldenaaksebaan, Belgium) for IHC and LA-ICPMS, or on ultralene foil for SR- $\mu$ XRF analysis. Movat's pentachrome, von Kossa, and Alcian blue ( $\mathrm{pH} 1.0)$ histologic staining, anti-smooth muscle cell (SMC) actin (antiSMA), and anti-rabbit macrophage (anti-RAM-11) immunostaining procedures were carried out on adjacent sections as described elsewhere [16]. Qualitative and score-based semiquantitative assessment of plaque pathomorphology was done by independent observers recording pathologic features defined by the American Heart Association (AHA) (electronic supplementary material, Table 1) [28]. Digital high-resolution scans of the histologic specimens were obtained at the Zentrale Biomaterialbank der Charité (ZeBanC).

\section{Laser Ablation Inductively Coupled Plasma Mass Spectrometry}

LA-ICP-MS analysis was performed on the sections adjacent to IHC sections. For that, an ICP-MS (Agilent 7900, Waldbronn, Germany) was coupled to a laser ablation system (NWR 213; New Wave Research, California, USA). Prior to analysis, sections were deparaffinized. Laser ablation was performed in continuous-line ablation mode with a circular laser spot size of $20 \mu \mathrm{m}$ at a scanning speed of $100 \mu \mathrm{m} \mathrm{s}^{-1}$ and $200 \mathrm{~ms}$ acquisition time with dailyoptimized output energies of $1.5 \mathrm{~J} \mathrm{~cm}^{-1}$. The method has been described elsewhere [29]. Ablated tissue was transported into the ICP-MS imager with helium gas at a flow of $0.9 \mathrm{~L} / \mathrm{min}$. Matrix-matched laboratory standards of well-defined element concentrations were spiked onto gelatin to quantify $\mathrm{Gd}$ and $\mathrm{Fe}$ (see also electronic supplementary material, Fig. S3). Fe concentration was determined by analysis of the isotope at mass 57 due to strong interference of ${ }^{40} \mathrm{Ar}^{16} \mathrm{O}$ with the most abundant isotope at mass 56 [30]. Gd and Eu signals were determined by analysis at mass 158 and 153 , respectively. Eu signal was only recorded in terms of counts per second (CPS) due to unavailability of standards. Generation of 2D distribution maps, image processing, and data evaluation were performed using MassImager, a free software developed by Robin Schmidt [31].

\section{Synchrotron X-Ray Fluorescence Spectroscopy}

SR- $\mu$ XRF investigations on the sections adjacent to those used in LA-ICP-MS analysis were done at the ID21 beamline at the European Synchrotron Radiation Facility in Grenoble, France [32]. Experiments were performed using the in-vacuum scanning X-ray spectroscopy setup, in which $\mathrm{X}$-rays were generated by undulators with an optimized gap size for $7.3 \mathrm{keV}$. The setup is explained in detail elsewhere [33]. The X-ray beam was focused down to $\sim 0.6 \times 0.8 \mu \mathrm{m}^{2}$ (vertical $\times$ horizontal) using a fixed-curvature KirkpatrickBaez mirror system. Flux was $\sim 5 \times 10^{10}$ photons/s $(\sim$ $180 \mathrm{~mA}$ SR current in multibunch mode). Acquisition time per pixel was $100 \mathrm{~ms}$. Pixel size for collecting the XRF maps was set to $30 \mu \mathrm{m}, 10 \mu \mathrm{m}, 1-2 \mu \mathrm{m}$, or $0.5 \mu \mathrm{m}$ depending on the size of the region of interest (ROI). Scans were acquired in continuous mode. Distribution maps of Fe, Gd, sulfur (S), $\mathrm{P}$, and $\mathrm{Ca}$ were generated. XRF normalization, spectral deconvolution, and quantification were done using the PyMCA software (see also electronic supplementary material, Fig. S4) [34]. Cellular uptake of Gd was investigated by analyzing the $\mathrm{P}$ distribution as a marker of cell membrane, ATP, or nucleic acids. P distribution maps at $0.5 \mu \mathrm{m}$ 

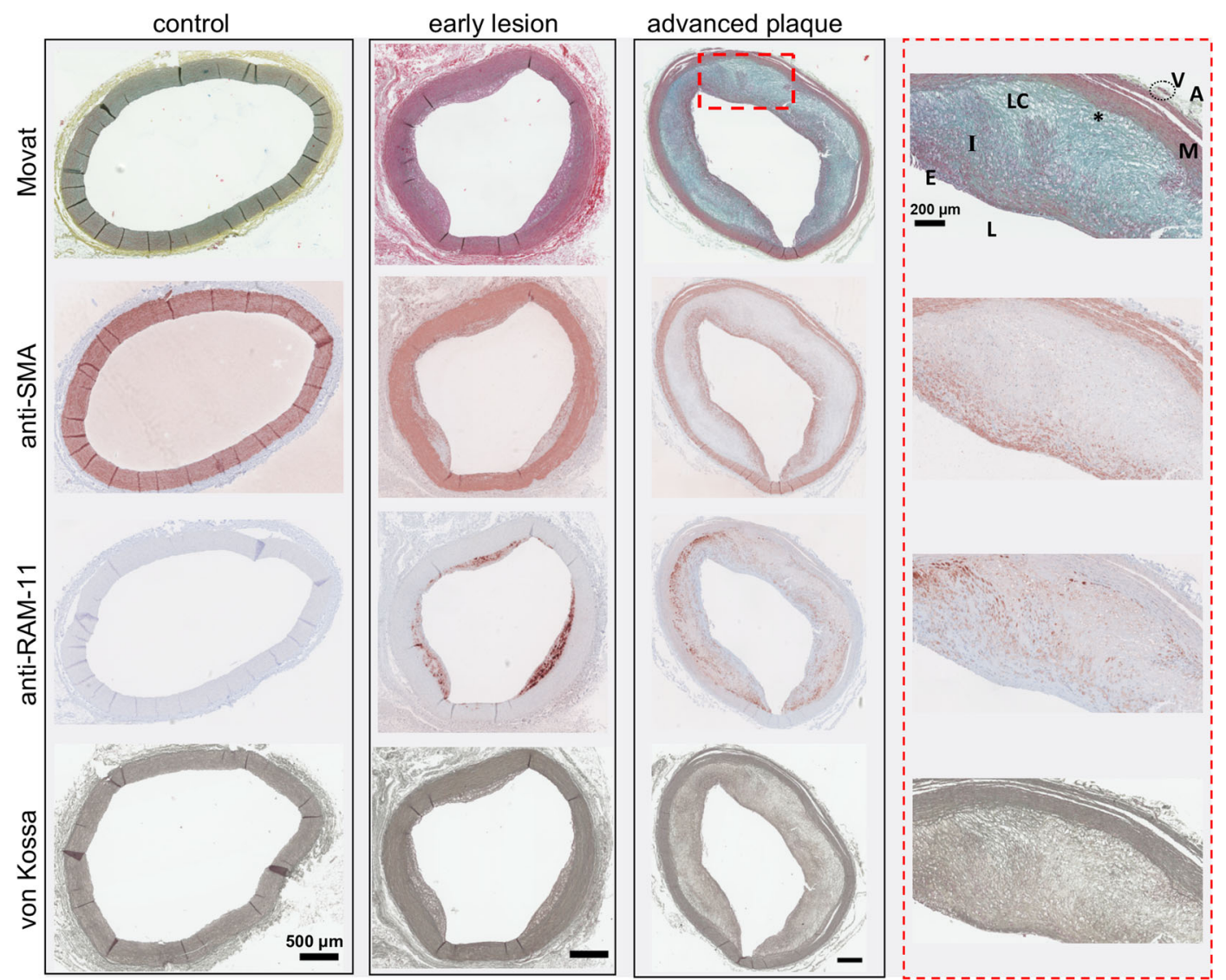

Fig. 1. Atherosclerotic plaque characterization by immunohistochemistry $(\mathrm{IHC})$. Advanced plaque region of interest $(\mathrm{ROI})(\times 10$ magnification) is provided for comparison. Movat's staining reveals cells by red staining that are also depicted by anti-smooth muscle cell (SMC) actin (anti-SMA) and anti-rabbit macrophage (anti-RAM-11) immunostaining. Contractile SMCs in the media and synthetic SMCs migrating into the intima are distinguished by their spindle-like and circular shapes, respectively. Lipid pools are nonstained circular, cleft-, or vacuole-like shapes at the intimomedial areas associated with increased macrophage colocalization, indicating foam cell or lipid cores. Lipid pools are surrounded by light blue-stained glycosaminoglycans (GAG). von Kossa staining identifies calcifications in the intima, especially along the intimomedial interface of advanced plaques. Scale bars, $500 \mu \mathrm{m}$; ROI, $200 \mu \mathrm{m}$; $L$, lumen; $E$, endothelium; I, intima; $L C$, lipid core; asterisk, intimomedial interface; $M$, media; $A$, adventitia; $V$, vasa vasorum.

resolution were segmented into two compartments by applying a $25 \%$ threshold on the maximum of the P K-line fluorescence signal and comparing elemental concentrations in P-poor $(<25 \%$ P-Threshold $)$ or P-rich $(>25 \% \mathrm{P}$ Threshold) areas. Corresponding spectral deconvolution displaying colocalizing elements was normalized by the number of pixel of each region, thus giving an averaged spectrum for each region. The amplitude of the peak corresponding to the respective element was scaled by the amount of atoms being probed by the X-ray beam. Size distribution analysis of $\mathrm{Gd}$ hotspots was done using the ImageJ software.

\section{Results}

IHC performed on adjacent sections of arterial specimens obtained from 14 rabbits revealed various degrees of atherosclerotic plaque formation. These were categorized into early lesion and advanced plaque using the pathologic plaque features defined by the AHA (Fig. 1, control: $n=2$, early lesion: $n=3$, advanced plaque: $n=9$, see electronic supplementary material Table 1). Movat's staining revealed the individual arterial vessel wall layers (adventitia, media, intima, and endothelium). Medial and endothelial regions were the major cellular areas, identified by red staining, which was also depicted by SMA and RAM-11 immunostaining. Contractile SMCs in the media and synthetic SMCs migrating into the intima were distinguishable by their spindle-like and circular shapes, respectively. Large lipid pools were seen as nonstaining circular, cleft-, or vacuolelike shapes mostly at the intimomedial interface associated with increased macrophage colocalization, indicating foam cell or lipid core formation. These were often surrounded by light blue-stained glycosaminoglycan (GAG) networks. Synthetic SMCs and stretches of yellow/green-stained collagen fibrils were observed covering the lipid pools. von 

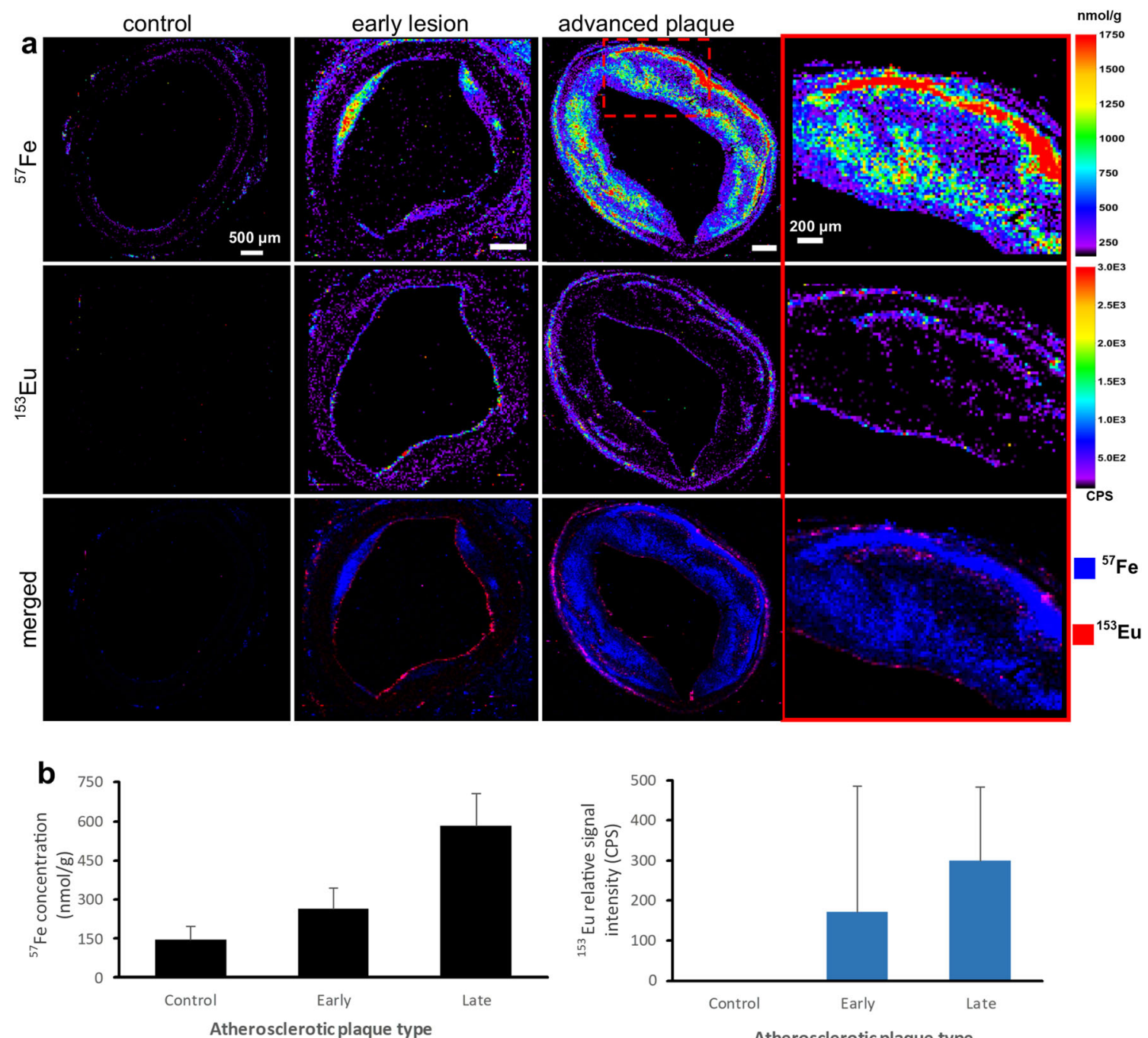

Atherosclerotic plaque type

Fig. 2. Europium (Eu)-doped very small superparamagnetic iron ( $\mathrm{Fe})$ oxide nanoparticle (Eu-VSOP) distribution in atherosclerotic plaques. a Laser ablation inductively coupled plasma mass spectrometry (LA-ICP-MS) elemental maps of ${ }^{57} \mathrm{Fe}^{1+}$ and ${ }^{153} \mathrm{Eu}^{1+}$ distribution. Advanced plaque ROI is provided for comparison. Eu-positive signal (recorded in counts per second, CPS) distinguishes Eu-VSOP distribution from that of endogenous Fe. No Eu signal is detected in controls; weaker Eu signal is detected in the media and the intima of early lesions. Eu signal intensity and Fe concentrations increase in advanced plaques. High Eu signal is confined to endothelium or to the intimomedial interface. Scale bars, $500 \mu \mathrm{m}, \mathrm{ROI}, 200 \mu \mathrm{m}$. b Graphs of Fe concentration and Eu signal intensity in atherosclerotic plaques. Fe concentrations: $146.17 \mathrm{nmol} / \mathrm{g}( \pm 52.58 \mathrm{nmol} / \mathrm{g})$ in healthy arteries, $264.89 \mathrm{nmol} / \mathrm{g}( \pm 79.23 \mathrm{nmol} / \mathrm{g})$ in early lesions, and $583.20 \mathrm{nmol} / \mathrm{g}( \pm 122.46 \mathrm{nmol} / \mathrm{g})$ in advanced plaques.

Kossa staining revealed intimal calcifications, especially along the intimomedial interface of advanced plaques (see also electronic supplementary material, Fig. S1).

Metal and nonmetal images obtained by elemental microscopy matched the pathomorphologic features identified by IHC with S distribution highlighting the anatomy of the arterial vessel wall layers, while $\mathrm{P}$ distribution corresponded well with cellular areas (Fig. 6). LA-ICP-MS revealed Gd or Fe distribution at $20-\mu \mathrm{m}$ resolution ( $x-y$ direction) with a LOD of $\sim 0.1 \mathrm{nmol} / \mathrm{g}$ for $\mathrm{Gd}$, and $\sim 100 \mathrm{nmol} / \mathrm{g}$ for Fe. No Eu signal was detected in controls (Fig. 2). Eu-positive signal identified the VSOP presence in the vessel wall, and by acting as a surrogate marker, it allowed the comparison of Eu-VSOP and endogenous $\mathrm{Fe}$ distribution in tissue sections. Weaker $\mathrm{Eu}$ signal was detected in the media and the intima of early lesions. Eu signal intensity and $\mathrm{Fe}$ concentrations were higher in larger plaques compared to smaller ones. High Eu signal was confined to endothelium or the intimomedial interface. $\mathrm{Fe}$ concentrations were $146.17 \mathrm{nmol} / \mathrm{g}( \pm 52.58 \mathrm{nmol} / \mathrm{g})$ in healthy arteries, $264.89 \mathrm{nmol} / \mathrm{g}( \pm 79.23 \mathrm{nmol} / \mathrm{g})$ in early lesions, and $583.20 \mathrm{nmol} / \mathrm{g}( \pm 122.46 \mathrm{nmol} / \mathrm{g})$ in advanced plaques.

In the control group (Eu-VSOP-negative, Gd-positive), Gd was detected (Fig. 3). In healthy arteries, Gd distribution was global and homogeneous. In early lesions, Gd was distributed inhomogeneously and concentrations were higher in the subendothelial space. Advanced plaques were 

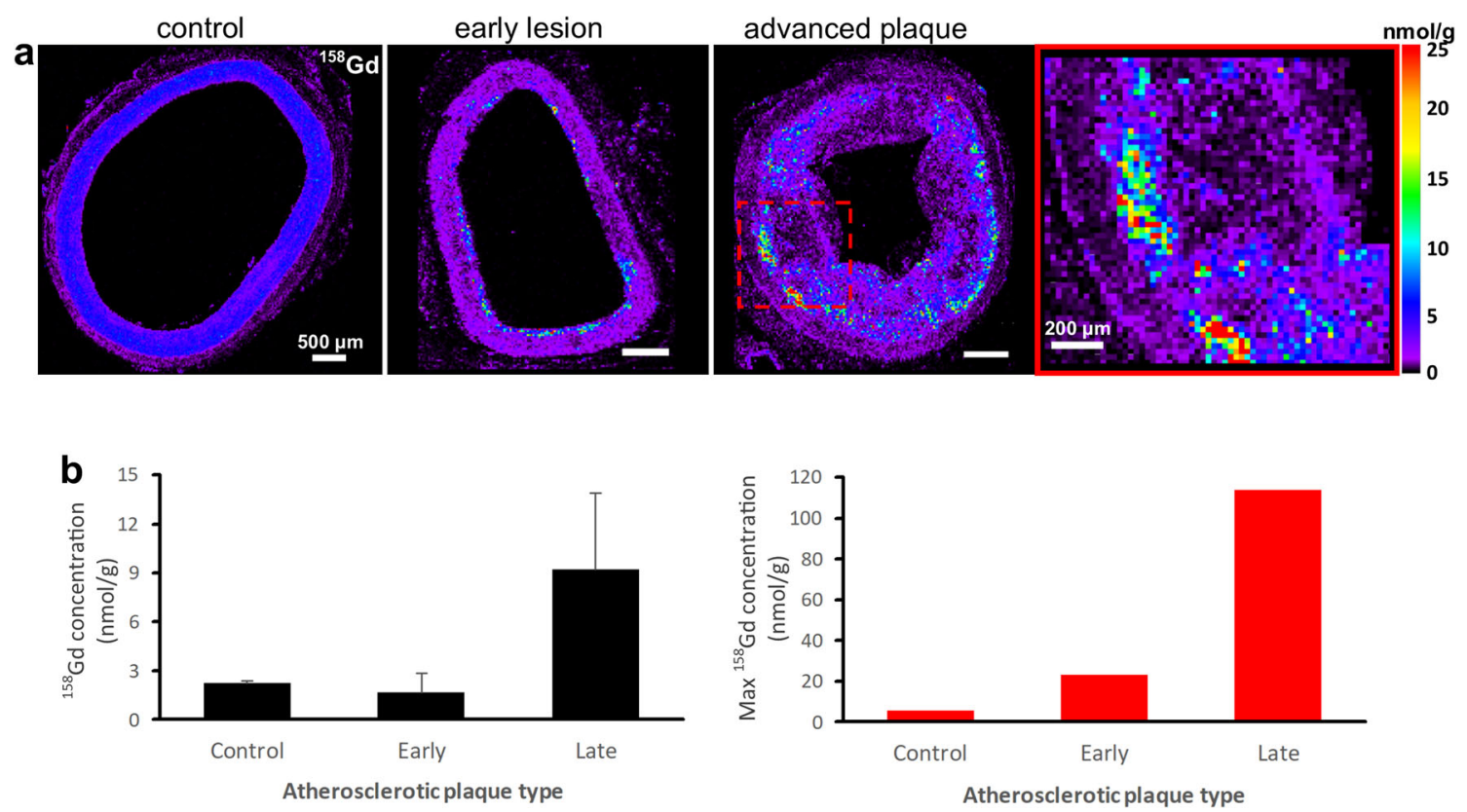

Fig. 3. Gadolinium (Gd) distribution in atherosclerotic plaques. a LA-ICP-MS elemental map of ${ }^{158} \mathrm{Gd}$ distribution. Advanced plaque $\mathrm{ROI}$ is provided for comparison. Gd is also detected in the control group (Eu-VSOP-negative, Gd-positive). In healthy arteries, Gd distribution is global and homogenous. In early lesions, Gd concentrations are higher in the subendothelial space. Advanced plaques are characterized by high focal Gd content at the intimomedial interface. Scale bars, $500 \mu \mathrm{m} ; \mathrm{ROI}, 200 \mu \mathrm{m}$. b Graphs of $\mathrm{Gd}$ and maximum $\mathrm{Gd}$ concentration in atherosclerotic plaques. Gd concentrations: $2.22 \mathrm{nmol} / \mathrm{g}( \pm 0.14 \mathrm{nmol} / \mathrm{g})$, $1.63 \mathrm{nmol} / \mathrm{g}( \pm 1.19 \mathrm{nmol} / \mathrm{g})$, and $9.23 \mathrm{nmol} / \mathrm{g}( \pm 4.64 \mathrm{nmol} / \mathrm{g})$, with maximum concentrations of $5.30 \mathrm{nmol} / \mathrm{g}, 22.85 \mathrm{nmol} / \mathrm{g}$, and $113.66 \mathrm{nmol} / \mathrm{g}$ in healthy arteries, early, and advanced plaques, respectively.

characterized by high focal Gd content at the intimomedial interface. Gd concentrations were $2.22 \mathrm{nmol} / \mathrm{g}( \pm 0.14 \mathrm{nmol} /$ g), $1.63 \mathrm{nmol} / \mathrm{g}( \pm 1.19 \mathrm{nmol} / \mathrm{g})$, and $9.23 \mathrm{nmol} / \mathrm{g}( \pm$ $4.64 \mathrm{nmol} / \mathrm{g}$ ), with maximum concentrations of $5.30 \mathrm{nmol} /$ $\mathrm{g}, 22.85 \mathrm{nmol} / \mathrm{g}$, and $113.66 \mathrm{nmol} / \mathrm{g}$ in healthy arteries, early, and advanced plaques, respectively.

SR- $\mu$ XRF analysis at $30-\mu \mathrm{m}$-step width detected $\mathrm{Gd}$ in 4 samples - one early lesion and 3 advanced plaques. Predefined ROIs within these specimens were further investigated for their Gd content at higher resolution down to $0.5 \mu \mathrm{m}$, which displayed increasing Gd concentrations (Fig. 4). Higherresolution scans revealed increasing local $\mathrm{Gd}, \mathrm{P}$, and $\mathrm{Ca}$ concentrations in progressing plaques (Figs. 4 and 5). SR$\mu \mathrm{XRF}$ analysis at $10-\mu \mathrm{m}$ - and $2-\mu \mathrm{m}$-step width and RGB overlay of $\mathrm{P}, \mathrm{S}$, and $\mathrm{Fe}$ maps revealed distinct $\mathrm{Fe}$ distribution around cell- or collagen-rich areas in the intima (Fig. 6). In comparison, RGB overlay of Gd, S, and Fe maps in addition to $\mathrm{P}, \mathrm{S}$, and Gd maps revealed Gd distribution within the deeper areas of the intima, especially along the intimomedial interface at increasing concentrations colocalized with $\mathrm{P}$ and $\mathrm{Ca}$. Finally, analysis of possible cellular uptake of Gd (see the "Materials and Methods" section) yielded Gd, $\mathrm{P}$, and Ca concentrations of $\sim 0.1 \mathrm{mM}, 62 \mathrm{mM}$, and $87 \mathrm{mM}$, respectively, in areas below the threshold (Fig. 7, electronic supplementary material, Fig. S5). In areas above the threshold, which indicates elemental hotspots, these concentrations were $\sim 2.5 \mathrm{mM}, 779 \mathrm{mM}$, and $789 \mathrm{mM}$, respectively. Size distribution analysis revealed Gdrich hotspots ranging from a few micrometers to submicrometers, which corroborated with von Kossa-stained calcified deposits.

\section{Discussion}

The aim of this study was to investigate the microdistribution of $\mathrm{Gd}$ - and iron oxide-based $\mathrm{CA}$ in the atherosclerotic plaques of NZW rabbits after IV injection of Eu-VSOP and GdBOPTA. VSOP are increasingly being investigated in MR imaging of experimental atherosclerosis owing to their early uptake $(<2 \mathrm{~h})$ into atherosclerotic plaques that correlates with accumulation of the ECM rather than phagocytosis $[15,16]$. ECM accumulation is a marker of atherosclerotic plaque progression; therefore, correlations of ECM material with Fe concentration, Eu signal intensity as a surrogate marker of VSOP, and Gd concentration were investigated [35]. Eudoping of the iron oxide cores of the nanoparticles enabled their detection by the LA-ICP-MS analysis and distinguished their distribution from that of endogenous Fe [26]. Overall, our results show correlations between ECM material and Fe concentration or Eu signal intensity.

Published data suggest that VSOP enter atherosclerotic plaques through the endothelium or macrophage phagocytosis [36]. In endothelial cells, uptake was shown to be mediated by endosomal pathway [37]. These findings are supported by our investigations, which demonstrate EuVSOP mostly along the endothelium, superficially in the subendothelial space and at the boundaries of the adventitia, 

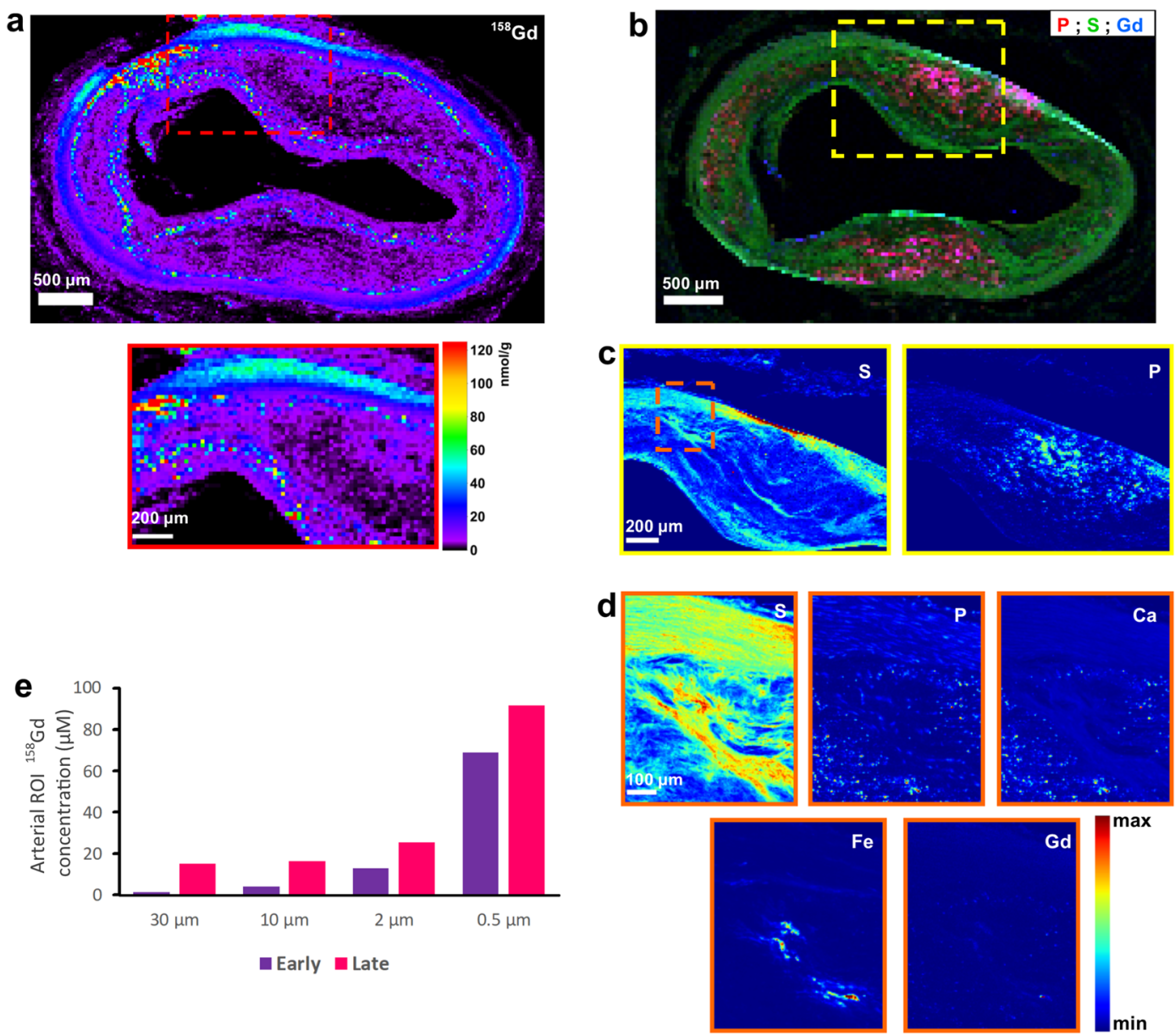

Fig. 4. Spatially resolved Gd distribution and elemental hotpots in atherosclerotic plaques. a LA-ICP-MS elemental map of ${ }^{158} \mathrm{Gd}$ distribution. Advanced plaque ROI is provided for comparison. Scale bars, $500 \mu \mathrm{m}$; ROI, $200 \mu \mathrm{m}$. b-d Synchrotron radiation $\mu \mathrm{X}$-ray fluorescence (SR- $\mu \mathrm{XRF}$ ) analysis at increasing resolution. b RGB overlay of phosphorus (P), sulfur (S), and Gd distribution at 30- $\mu \mathrm{m}$ resolution. c ROI elemental maps of $S$ and $P$ at $10-\mu \mathrm{m}$ resolution reveal arterial vessel wall anatomy and cellular zones. d ROI elemental maps of S, P, calcium (Ca), Fe, and Gd at 2- $\mu$ m resolution. Scale bars: b1, 500 $\mu \mathrm{m}$; b2, $200 \mu \mathrm{m}$; b3, $50 \mu \mathrm{m}$. e SR- $\mu$ XRF analysis in both early lesions and advanced plaques reveals increasing ROI Gd concentrations with increasing spatial resolution.

media, and intima (Fig. 2). Although Eu detection remained beyond the sensitivity of SR- $\mu$ XRF, RGB overlays of P, S, and Fe maps highlighted Fe distribution in cell- or collagenrich areas (Fig. 6). Cells respond to changes in $\mathrm{Fe}$ concentration by interactions involving Fe transport, Fe-S clustering or storage proteins, and highly sulfated GAGs [38]. IONP can be metabolized to soluble Fe, which might be stored as ferritin or released into an inflammatory environment [39]. Increased vasa vasorum activity results in the formation of fragile microvessels that might enhance nanoparticle uptake into the plaque ECM (Fig. 1, electronic supplementary material, Fig. S2) [40].

Gd concentration, unlike that of Fe, did not correlate with increased ECM material. Remarkably though, compared to healthy arteries, maximum Gd concentrations were 4 and 21 times higher in early and advanced plaques, respectively. This indicates focal Gd hotspots. Advanced plaques were characterized by a large number of such hotspots in deeper regions of the intima corresponding to the intimomedial interface, which hosts large lipid pools and macrophages (Figs. 1 and 3). In ROIs including such areas, SR- $\mu$ XRF analysis at $\sim 0.5-\mu \mathrm{m}$ resolution confirmed Gd content exceeding $\mathrm{mM}$ concentrations with high $\mathrm{P}$ and $\mathrm{Ca}$ colocalization (Fig. 5). These results are in line with studies suggesting insoluble complex formation $[20$, 21]. An earlier study suggests that Gd uptake into atherosclerotic plaques occurs through binding and complexation with serum albumin and breakdown of Gd-chelates at the endothelium or vasa vasorum [41]. The authors of this study postulate ECM accumulation of Gd through interactions with collagen, proteoglycans, and tenascin [41]. Another study identified the integrity of the collagen network in cartilage to be a determinant of gadopentetate dimeglumine (Magnevist) accumulation [42]. Our results are consistent with these findings in that dense stretches of collagen fibrils resulted in boundary formation around lipid-rich zones (Fig. 6, electronic supplementary material, Fig. S1). This might lead to selective Gd 


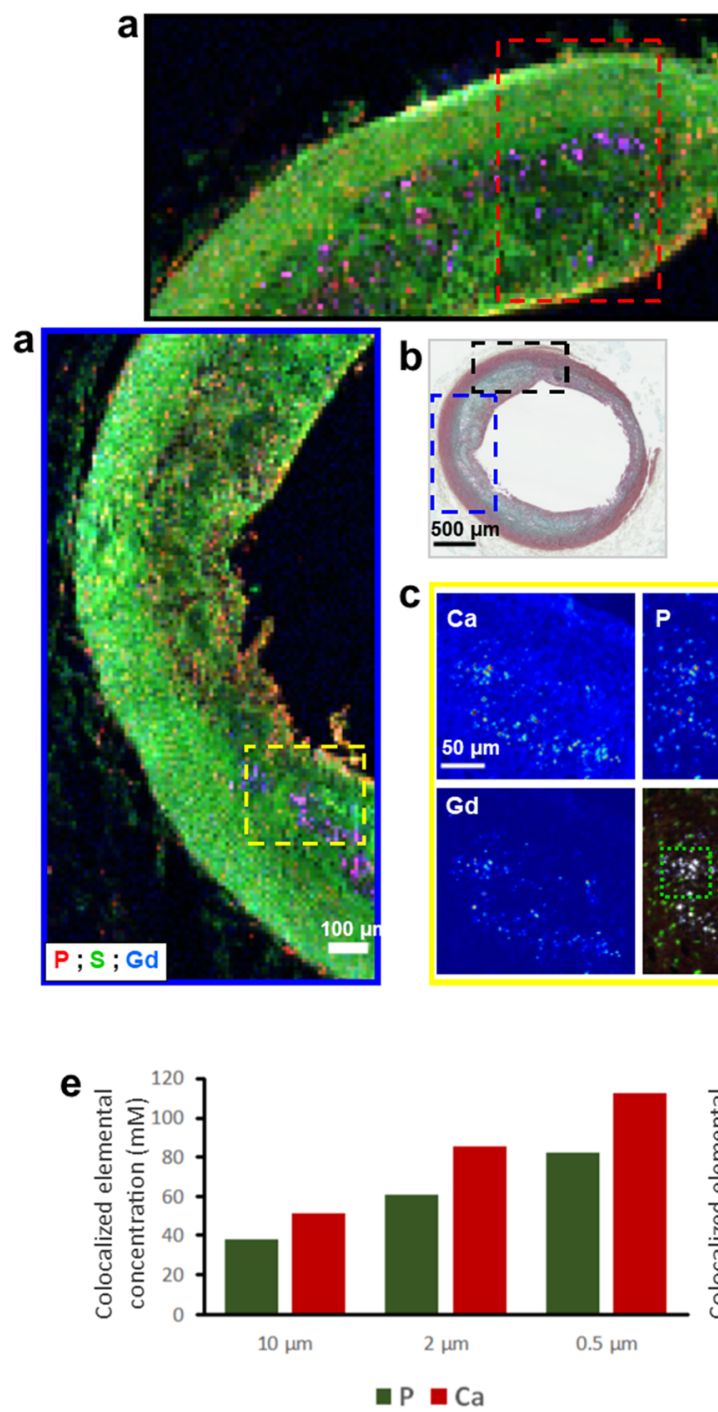

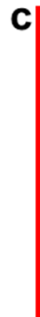
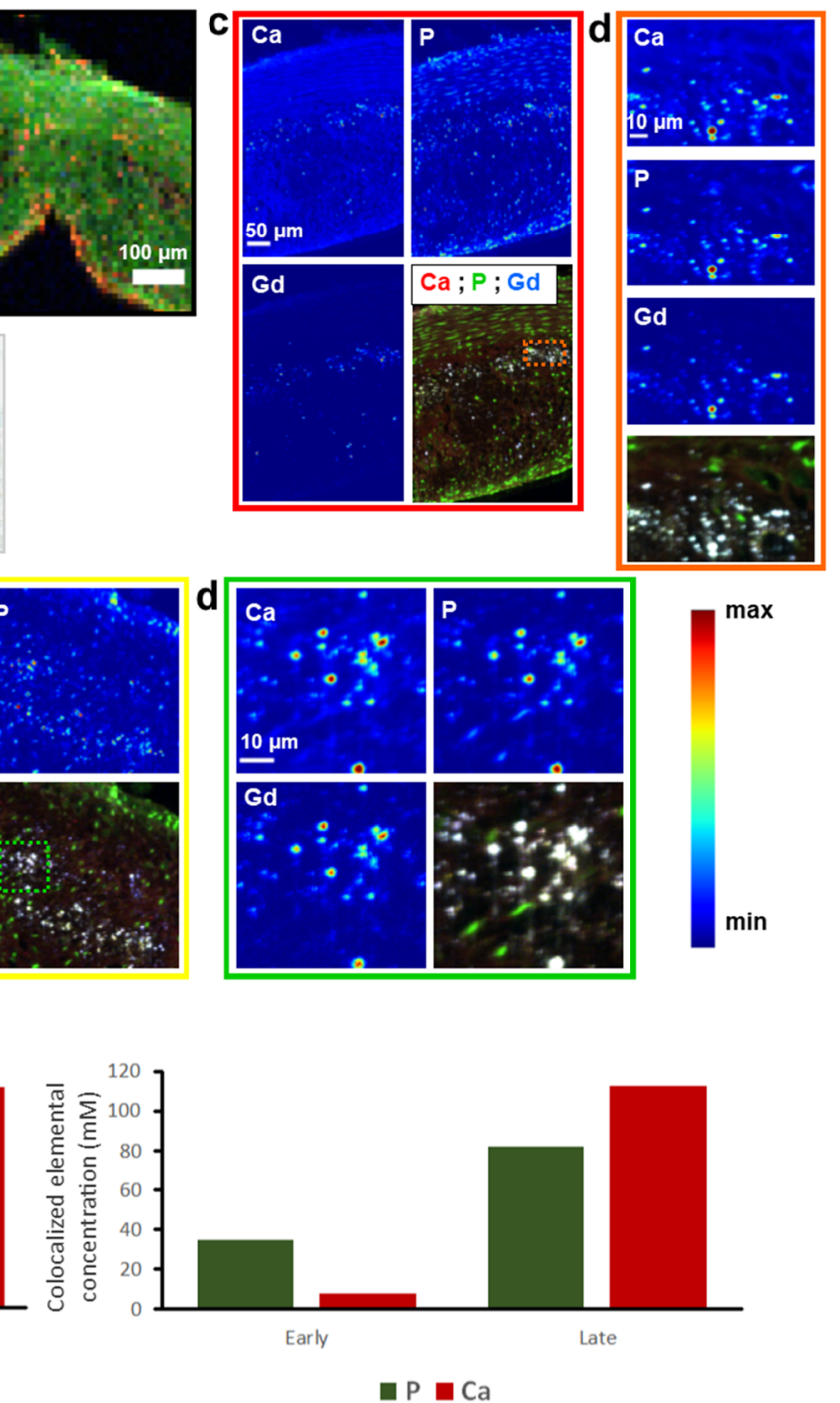

Fig. 5. Spatially resolved Gd hotpots and colocalization of $P$ and $C a$ in atherosclerotic plaques. SR- $\mu$ XRF analysis results of 2 ROls in an advanced plaque are provided for comparison. a RGB overlay P, S, and Gd distribution at 10- $\mu$ m resolution. Scale bars, $100 \mu \mathrm{m}$. b Movat's staining micrograph is provided for an overview. c Elemental maps and RGB overlay of Ca, P, and Gd distribution at $2-\mu \mathrm{m}$ resolution. Scale bars, $50 \mu \mathrm{m}$. d Elemental maps and RGB overlay of Ca, P, and Gd distribution at 0.5- $\mu \mathrm{m}$ resolution. Scale bars, $10 \mu \mathrm{m}$. e SR- $\mathrm{XXRF}$ analysis of $\mathrm{Gd}$ hotspots reveals higher $\mathrm{P}$ and Ca concentrations in progressing plaques (right), and concentrations further increase with increasing spatial resolution (left).

deposition along the lipid pool-rich intimomedial interface or Gd concentration gradients, possibly through interactions with GAGs. GAGs are upregulated during plaque progression [43]. Their highly negatively charged side chains contribute to complex formation through establishing electrostatic bridges or performing higher level of interactions especially with positive amino-acid residues of proteins including low density lipoprotein (LDL), platelet factor-4 (PF4), or fibroblast growth factor-2 (FGF-2) [44]. This ability makes them excellent candidates for ligand competition reactions, especially through facilitation of highly abundant divalent or trivalent cations, which stabilize these complexes [45]. Although Gd-BOPTA is negatively charged, it is likely to undergo partial or complete chelate dissociation in metabolically active inflammatory sites of the atherosclerotic ECM. Notably, the MRI signal-enhancing effect of Gd was reported to increase dramatically after GBCA incubation including Gd-BOPTA in heparin, which is a highly sulfated GAG type [21].

Finally, although GBCA were originally developed to distribute extracellularly after IV administration, it has been speculated that reactive cellular responses may occur [46]. Inhibition of phagocytosis and macrophage apoptosis upon Gd exposure have been reported [47, 48]. The threshold we applied on the fluorescence signal detected for the $\mathrm{P}$ distribution at 0.5$\mu \mathrm{m}$ resolution analyzed by SR- $\mu \mathrm{XRF}$ corroborates a cellular response since high P distribution marks cell membrane, ATP, or nucleic acids. Increased $\mathrm{Gd}, \mathrm{P}$, and $\mathrm{Ca}$ concentrations in areas above the threshold confirm Gd hotspots and further support complexation with $\mathrm{P}$ and $\mathrm{Ca}$. The size distribution of these 

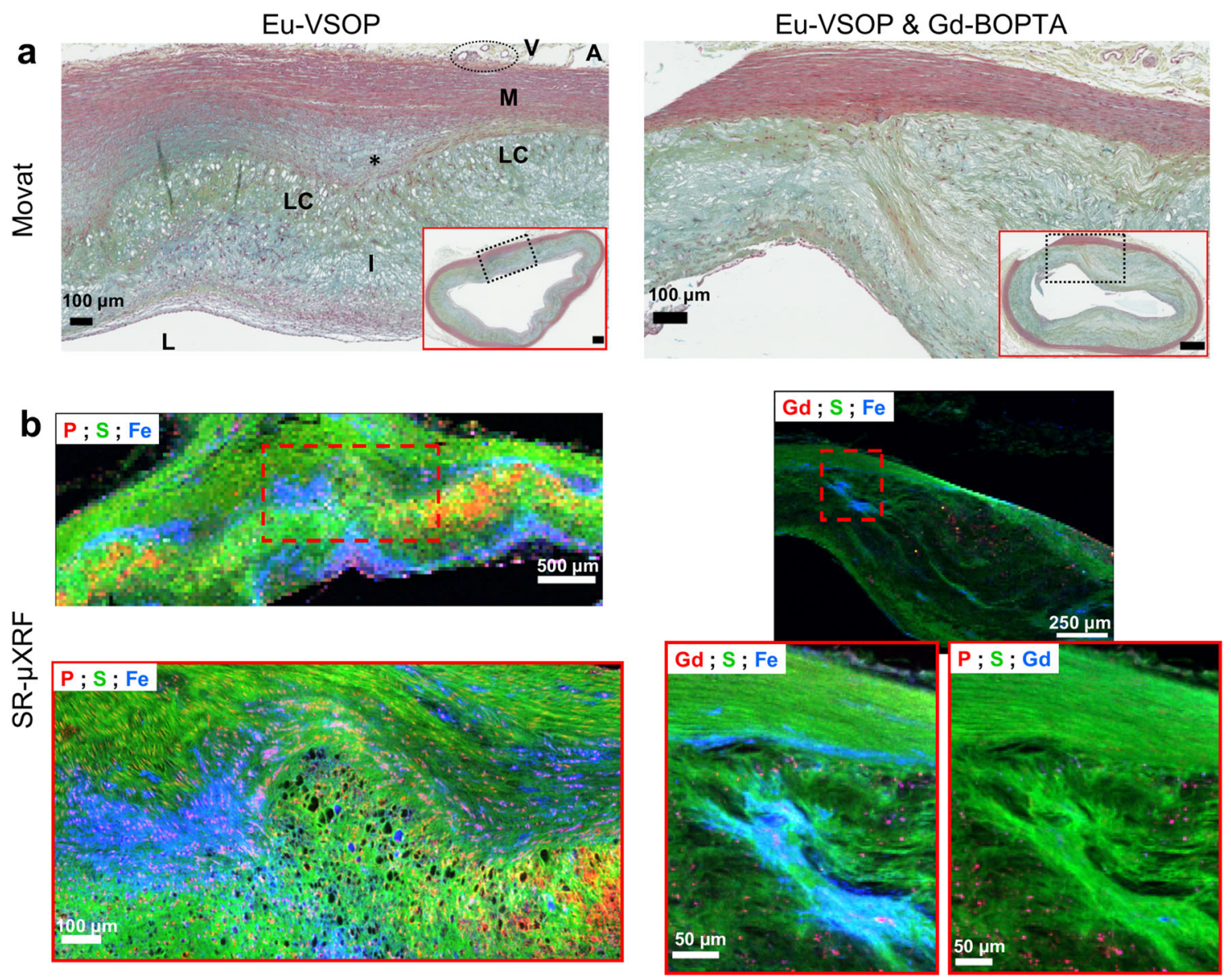

Fig. 6. Comparative microdistribution of Fe and $\mathrm{Gd}$ in atherosclerotic plaques. Rabbits were intravenously injected with either Eu-VSOP alone (left) or Eu-VSOP and Gd-BOPTA (right). a Microscopic characterization of Movat's stained advanced plaque pathomorphology. (ROIs, $\times 10$ magnification). Synthetic SMCs and dense stretches of yellow/green-stained collagen fibrils are seen covering the lipid pools. Scale bars, $500 \mu \mathrm{m}$; ROI, $100 \mu \mathrm{m}$. b SR- $\mu$ XRF analysis at 10- $\mu \mathrm{m}$ and $2-\mu \mathrm{m}$ resolution (ROls are indicated by red dashed lines). RGB overlay of P, S, and Fe maps demonstrates distinct Fe distribution in cell- or collagen-rich areas in the intima or at the boundary between the media and intima (left; scale bars, $500 \mu \mathrm{m}$; ROI, $100 \mu \mathrm{m}$ ). RGB overlay of Gd, $\mathrm{S}$, and Fe maps in addition to P, S, and Gd maps revealed Gd distribution within the deeper areas of the intima, especially along the intimomedial interface at highly increasing concentrations colocalized with $\mathrm{P}$ and $\mathrm{Ca}$, distinguishing Gd distribution from that of Eu-VSOP (right; scale bars, $250 \mu \mathrm{m}$; ROI, $50 \mu \mathrm{m}$ ). L, lumen; I, intima; LC, lipid core; asterisk, intimomedial interface; $M$, media; $\boldsymbol{A}$, adventitia; $\boldsymbol{V}$, vasa vasorum.

hotspots ranging from a few micrometers to submicrometers indicates Gd involvement in arterial calcification, presumably through uptake by cells that undergo calcified apoptosis or extracellular mineralization (Fig. 7, electronic supplementary material, Fig. S5) [49]. Arterial calcification is an active and highly regulated process of atherogenesis. It is similar to bone formation, occurs parallel to arterial lipid build-up, and becomes a key characteristic of advanced plaques [50]. We detected such calcifying regions in advanced plaque sections, especially in microzones along the intimomedial interface colocalizing with Gd hotspots (Figs. 1 and 7).

Our study has several limitations including sample processing and the small sample size. Investigation of a larger sample set in this study would have been excessively demanding and not feasible for elemental microscopy during our granted beam time at the European Synchrotron Radiation Facility. Sample processing by means of tissue fixation and paraffin embedding is a standard method in IHC analysis. Paraffin infiltration facilitates uniform slicing and reproducibility of serial sectioning, although it might also result in capture of elements. We performed deparaffinization before LA-ICP-MS analysis; however, ethanol-washing steps during this process might have altered the measured elemental concentrations we measured, particularly for elements involved in transient interactions.

\section{Conclusion}

This is the first study comparing the microdistribution of Gd- and iron oxide-based MR contrast agents in atherosclerotic plaques. We performed IHC and correlative elemental microscopy by LA-ICP-MS and SR- $\mu \mathrm{XRF}$, and achieved a 

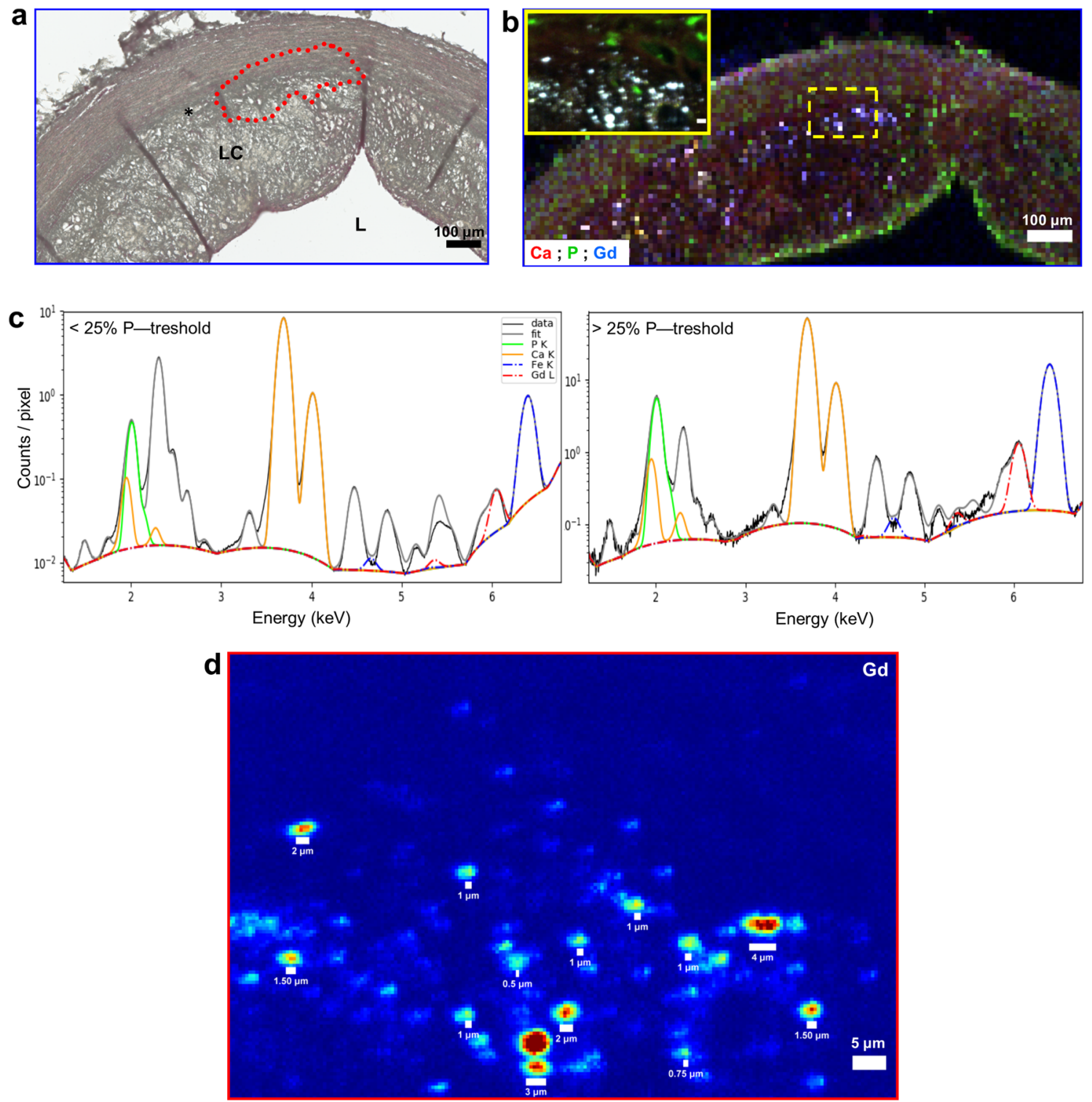

Fig. 7. Gd involvement in arterial calcification. a Micrograph of a von Kossa-stained advanced plaque ROI (× 15 magnification) reveals arterial calcifications, which are enriched at the intimomedial interface (asterisk, also indicated by the dashed red lines). Scale bar, $100 \mu \mathrm{m}$; $L$, lumen; $L C$, lipid core. b SR- $\mu$ XRF analysis and RGB overlay of $\mathrm{Ca}, \mathrm{P}$, and Gd distribution at $10-\mu \mathrm{m}$ and $0.5-\mu \mathrm{m}$ resolution (ROls are marked by yellow dashed lines). Scale bars, $100 \mu \mathrm{m}$; ROI, $5 \mu \mathrm{m}$. c Cellular uptake of Gd is investigated by analyzing the $\mathrm{P}$ distribution as a marker of cell membrane, ATP, or nucleic acids. P distribution maps at $0.5-\mu m$ resolution are segmented into two compartments by applying a $25 \%$ threshold on the maximum of the P K-line fluorescence signal and comparing elemental concentrations in P-poor ( $<25 \%$ P-Threshold) or P-rich ( $>25 \%$ P-Threshold) areas. Corresponding spectral deconvolution displaying colocalizing elements are normalized by the number of pixel of each region, thus giving an averaged spectrum for each region. The amplitude of the peak corresponding to the respective element is scaled by the amount of atoms being probed by the X-ray beam. In contrast to P-poor areas with $<1 \mathrm{mM}, 62 \mathrm{mM}$, and $87 \mathrm{mM}$ of $\mathrm{Gd}$, $\mathrm{P}$ and $\mathrm{Ca}$, respectively, P-rich areas contained $>2 \mathrm{mM}, 779 \mathrm{mM}$, and $789 \mathrm{mM}$ of $\mathrm{Gd}$, P and Ca, respectively. Since P-rich compartments mark the cells or indicate close proximity to the cells, Gd could have been taken up by the cells, presumably by those that undergo calcified apoptosis, or may be involved in extracellular mineralization through complexation with $\mathrm{P}$ and Ca. d Size distribution analysis shows Gd-rich hotspots ranging from a few micrometers to submicrometers, which corroborates with von Kossa-stained calcified deposits, and indicates Gd involvement in arterial calcification.

limit of detection at $\sim 0.1 \mathrm{nmol} / \mathrm{g}$ and a spatial resolution at $0.5 \mu \mathrm{m}$. Overall, these methods allowed differentiation of atherosclerotic plaque tissue distributions of Eu-VSOP and Gd, which are determined by the microstructural ECM composition. We found arterial vessel wall $\mathrm{Fe}$ concentration and $\mathrm{Eu}$ signal intensity to increase with atherosclerotic plaque progression, suggesting that Eu-VSOP might be used to monitor plaque progression by experimental MRI 
investigations. Furthermore, we found that the intimomedial interface is a crucial microenvironment for Gd-rich elemental hotspots. Colocalization of increased $\mathrm{Ca}$ and $\mathrm{P}$ and the size distribution of $\mathrm{Gd}$ hotspots ranging from a few micrometers to submicrometers indicate arterial calcification, which might help in characterizing morphological changes underlying plaque vulnerability, and in turn pave the way for MRI signal intensity-based discrimination of stable plaques from vulnerable plaques.

Supplementary Information. The online version contains supplementary material available at https://doi.org/10.1007/s11307-020-01563-z.

Acknowledgements. Open Access funding enabled and organized by Projekt DEAL. We acknowledge excellent cooperation with the European Synchrotron Radiation Facility (ESRF), which allocated beamline ID21 beamtime (proposal number: MD-1163), and Zentrale Biomaterialbank der Charité (ZeBanC). We thank Janni Breinl for her contribution in the earlier MRI study. We also thank Dr. Antje Ludwig, Dr. Judith Bergs, Prof. Dr. Tobias Schäffter, and Prof. Dr. Ingolf Sack for their valuable support, Rafet Güven for graphical artwork, and Bettina Herwig for language editing.

Funding. This work was supported by Deutsche Forschungsgemeinschaft (German Research Foundation, DFG), Grant/Award Number: GRK 2260, BIOQIC, and SFB 1340, Matrix in Vision.

\section{Compliance with Ethical Standards}

\section{Conflict of Interest}

The authors declare that they have no conflict of interest.

Open Access This article is licensed under a Creative Commons Attribution 4.0 International License, which permits use, sharing, adaptation, distribution and reproduction in any medium or format, as long as you give appropriate credit to the original author(s) and the source, provide a link to the Creative Commons licence, and indicate if changes were made. The images or other third party material in this article are included in the article's Creative Commons licence, unless indicated otherwise in a credit line to the material. If material is not included in the article's Creative Commons licence and your intended use is not permitted by statutory regulation or exceeds the permitted use, you will need to obtain permission directly from the copyright holder. To view a copy of this licence, visit http:// creativecommons.org/licenses/by/4.0/.

\section{References}

1. Benjamin EJ, Blaha MJ, Chiuve SE, Cushman M, Das SR, Deo R, de Ferranti SD, Floyd J, Fornage M, Gillespie C, Isasi CR, Jiménez MC, Jordan LC, Judd SE, Lackland D, Lichtman JH, Lisabeth L, Liu S, Longenecker CT, Mackey RH, Matsushita K, Mozaffarian D, Mussolino ME, Nasir K, Neumar RW, Palaniappan L, Pandey DK, Thiagarajan RR, Reeves MJ, Ritchey M, Rodriguez CJ, Roth GA, Rosamond WD, Sasson C, Towfighi A, Tsao CW, Turner MB, Virani SS, Voeks JH, Willey JZ, Wilkins JT, Wu JH, Alger HM, Wong SS, Muntner P, American Heart Association Statistics Committee and Stroke Statistics Subcommittee (2017) Heart Disease and Stroke Statistics-2017 update: a report from the American Heart Association. Circulation 135:e146-e603

2. Davies MJ (1996) Stability and instability: two faces of coronary atherosclerosis: the Paul Dudley White Lecture 1995. Circulation 94:2013-2020

3. Voros S, Rinehart S, Qian Z, Joshi P, Vazquez G, Fischer C, Belur P, Hulten E, Villines TC (2011) Coronary atherosclerosis imaging by coronary CT angiography: current status, correlation with intravascular interrogation and meta-analysis. JACC Cardiovasc Imaging 4:537-548

4. Skagen K, Johnsrud K, Evensen K, Scott H, Krohg-Sørensen K, Reier-Nilsen F, Revheim ME, Fjeld JG, Skjelland M, Russell D (2015) Carotid plaque inflammation assessed with ${ }^{18} \mathrm{~F}$-FDG PET/CT is higher in symptomatic compared with asymptomatic patients. Int $\mathrm{J}$ Stroke 10:730-736

5. Kilic ID, Caiazzo G, Fabris E, Serdoz R, Abou-Sherif S, Madden S, Moreno PR, Goldstein J, di Mario C (2015) Near-infrared spectroscopy-intravascular ultrasound: scientific basis and clinical applications. Eur Heart J Cardiovasc Imaging 16:1299-1306

6. Tearney GJ, Regar E, Akasaka T, Adriaenssens T, Barlis P, Bezerra HG, Bouma B, Bruining N, Cho JM, Chowdhary S, Costa MA, de Silva R, Dijkstra J, di Mario C, Dudeck D, Falk E, Feldman MD, Fitzgerald P, Garcia H, Gonzalo N, Granada JF, Guagliumi G, Holm NR, Honda Y, Ikeno F, Kawasaki M, Kochman J, Koltowski L, Kubo T, Kume T, Kyono H, Lam CCS, Lamouche G, Lee DP, Leon MB, Maehara A, Manfrini O, Mintz GS, Mizuno K, Morel MA, Nadkarni S, Okura H, Otake H, Pietrasik A, Prati F, Räber L, Radu MD, Rieber J, Riga M, Rollins A, Rosenberg M, Sirbu V, Serruys PWJC, Shimada K, Shinke T, Shite J, Siegel E, Sonada S, Suter M, Takarada S, Tanaka A, Terashima M, Troels T, Uemura S, Ughi GJ, van Beusekom HMM, van der Steen AFW, van Es GA, van Soest G, Virmani R, Waxman S, Weissman NJ, Weisz G (2012) Consensus standards for acquisition, measurement, and reporting of intravascular optical coherence tomography studies: a report from the International Working Group for Intravascular Optical Coherence Tomography Standardization and Validation. J Am Coll Cardiol 59:1058-1072

7. Garcia-Garcia HM, Mintz GS, Lerman A et al (2009) Tissue characterisation using intravascular radiofrequency data analysis: recommendations for acquisition, analysis, interpretation and reporting. Eurointervention J Eur Collab Work Group. Interv Cardiol Eur Soc Cardiol 5:177-189

8. Corti R, Fuster V (2011) Imaging of atherosclerosis: magnetic resonance imaging. Eur Heart J 32:1709-1719

9. Sosnovik DE, Nahrendorf M, Weissleder R (2007) Molecular magnetic resonance imaging in cardiovascular medicine. Circulation 115:2076-2086

10. Majmudar MD, Nahrendorf M (2012) Cardiovascular molecular imaging: the road ahead. J Nucl Med 53:673-676

11. Michalska M, Machtoub L, Manthey HD, Bauer E, Herold V, Krohne G, Lykowsky G, Hildenbrand M, Kampf T, Jakob P, Zernecke A, Bauer WR (2012) Visualization of vascular inflammation in the atherosclerotic mouse by ultrasmall superparamagnetic iron oxide vascular cell adhesion molecule-1-specific nanoparticles. Arterioscler Thromb Vasc Biol 32:2350-2357

12. Weissleder R, Lee AS, Khaw BA, Shen T, Brady TJ (1992) Antimyosin-labeled monocrystalline iron oxide allows detection of myocardial infarct: MR antibody imaging. Radiology 182:381-385

13. Kolodgie FD, Petrov A, Virmani R, Narula N, Verjans JW, Weber DK, Hartung D, Steinmetz N, Vanderheyden JL, Vannan MA, Gold HK, Reutelingsperger CPM, Hofstra L, Narula J (2003) Targeting of apoptotic macrophages and experimental atheroma with radiolabeled Annexin V: a technique with potential for noninvasive imaging of vulnerable plaque. Circulation 108:3134-3139

14. Sadat U, Usman A, Gillard JH (2017) Imaging pathobiology of carotid atherosclerosis with ultrasmall superparamagnetic particles of iron oxide: an update. Curr Opin Cardiol 32:437-440

15. Ludwig A, Poller WC, Westphal K, Minkwitz S, Lättig-Tünnemann G, Metzkow S, Stangl K, Baumann G, Taupitz M, Wagner S, Schnorr J, Stangl V (2013) Rapid binding of electrostatically stabilized iron oxide nanoparticles to THP-1 monocytic cells via interaction with glycosaminoglycans. Basic Res Cardiol 108:328

16. Wagner S, Schnorr J, Ludwig A, Stangl V, Ebert M, Hamm B, Taupitz M (2013) Contrast-enhanced MR imaging of atherosclerosis using citrate-coated superparamagnetic iron oxide nanoparticles: calcifying microvesicles as imaging target for plaque characterization. Int J Nanomedicine 8:767-779

17. Grobner T (2006) Gadolinium - a specific trigger for the development of nephrogenic fibrosing dermopathy and nephrogenic systemic fibrosis? Nephrol Dial Transplant 21:1104-1108

18. Fingerhut S, Niehoff AC, Sperling M, Jeibmann A, Paulus W, Niederstadt T, Allkemper T, Heindel W, Holling M, Karst U (2018) Spatially resolved quantification of gadolinium deposited in the brain 
of a patient treated with gadolinium-based contrast agents. J Trace Elem Med Biol 45:125-130

19. Swaminathan S, High WA, Ranville J, Horn TD, Hiatt K, Thomas M, Brown HH, Shah SV (2008) Cardiac and vascular metal deposition with high mortality in nephrogenic systemic fibrosis. Kidney Int 73:1413-1418

20. Laurent S, Vander EL, Henoumont C et al (2010) How to measure the transmetallation of a gadolinium complex. Contrast Media Mol Imaging 5:305-308

21. Taupitz M, Stolzenburg N, Ebert M, Schnorr J, Hauptmann R, Kratz H, Hamm B, Wagner S (2013) Gadolinium-containing magnetic resonance contrast media: investigation on the possible transchelation of $\mathrm{Gd} \mathrm{3}+$ to the glycosaminoglycan heparin: GdCM, Glycosaminoglycans and Transchelation. Contrast Media Mol Imaging 8:108-116

22. Ortega R, Devès G, Carmona A (2009) Bio-metals imaging and speciation in cells using proton and synchrotron radiation X-ray microspectroscopy. J R Soc Interface 6:S649-S658

23. Becker JS, Matusch A, Wu B (2014) Bioimaging mass spectrometry of trace elements - recent advance and applications of LA-ICP-MS: a review. Anal Chim Acta 835:1-18

24. de Schellenberger AA, Hauptmann R, Millward JM, Schellenberger E, Kobayashi Y, Taupitz M, Infante-Duarte C, Schnorr J, Wagner S (2017) Synthesis of europium-doped VSOP, customized enhancer solution and improved microscopy fluorescence methodology for unambiguous histological detection. J Nanobiotechnol 15:71

25. Taupitz M, Wagner S, Schnorr J et al (2004) Phase I clinical evaluation of citrate-coated monocrystalline very small superparamagnetic iron oxide particles as a new contrast medium for magnetic resonance imaging. Investig Radiol 39:394-405

26. Kobayashi Y, Hauptmann R, Kratz H, Ebert M, Wagner S, Taupitz M (2017) Europium doping of superparamagnetic iron oxide nanoparticles enables their detection by fluorescence microscopy and for quantitative analytics. Technol Health Care 25:457-470

27. Makowski MR, Wiethoff AJ, Blume U, Cuello F, Warley A, Jansen CHP, Nagel E, Razavi R, Onthank DC, Cesati RR, Marber MS, Schaeffter T, Smith A, Robinson SP, Botnar RM (2011) Assessment of atherosclerotic plaque burden with an elastin-specific magnetic resonance contrast agent. Nat Med 17:383-388

28. Virmani R, Kolodgie FD, Burke AP, Farb A, Schwartz SM (2000) Lessons from sudden coronary death: a comprehensive morphological classification scheme for atherosclerotic lesions. Arterioscler Thromb Vasc Biol 20:1262-1275

29. Lohrke J, Frisk AL, Frenzel T, Schöckel L, Rosenbruch M, Jost G, Lenhard DC, Sieber MA, Nischwitz V, Küppers A, Pietsch H (2017) Histology and gadolinium distribution in the rodent brain after the administration of cumulative high doses of linear and macrocyclic gadolinium-based contrast agents. Investig Radiol 52:324-333

30. Scharlach C, Müller L, Wagner S, Kobayashi Y, Kratz H, Ebert M, Jakubowski N, Schellenberger E (2016) LA-ICP-MS allows quantitative microscopy of europium-doped Iron oxide nanoparticles and is a possible alternative to ambiguous Prussian blue iron staining. $\mathrm{J}$ Biomed Nanotechnol 12:1001-1010

31. Radbruch A, Richter H, Fingerhut S, Martin LF, Xia A, Henze N, Paulus W, Sperling M, Karst U, Jeibmann A (2019) Gadolinium deposition in the brain in a large animal model: comparison of linear and macrocyclic gadolinium-based contrast agents. Investig Radiol 54:531-536

32. Cotte M, Pouyet E, Salomé M, Rivard C, de Nolf W, Castillo-Michel H, Fabris T, Monico L, Janssens K, Wang T, Sciau P, Verger L, Cormier L, Dargaud O, Brun E, Bugnazet D, Fayard B, Hesse B, Pradas del Real AE, Veronesi G, Langlois J, Balcar N, Vandenberghe Y, Solé VA, Kieffer J, Barrett R, Cohen C, Cornu C, Baker R, Gagliardini E, Papillon E, Susini J (2017) The ID21 X-ray and infrared microscopy beamline at the ESRF: status and recent applications to artistic materials. J Anal At Spectrom 32:477-493

33. Wang S, Hesse B, Roman M, Stier D, Castillo-Michel H, Cotte M, Suuronen JP, Lagrange A, Radbruch H, Paul F, Taupitz M, Schellenberger E, Sack I, Infante-Duarte C (2019) Increased retention of gadolinium in the inflamed brain after repeated administration of gadopentetate dimeglumine: a proof-of-concept study in mice combining ICP-MS and micro- and nano-SR-XRF. Investig Radiol 54:617-626

34. Veronesi G, Deniaud A, Gallon T, Jouneau PH, Villanova J, Delangle P, Carrière M, Kieffer I, Charbonnier P, Mintz E, Michaud-Soret I (2016) Visualization, quantification and coordination of $\mathrm{Ag}+$ ions released from silver nanoparticles in hepatocytes. Nanoscale 8:1701217021

35. Katsuda S, Kaji T (2003) Atherosclerosis and extracellular matrix. J Atheroscler Thromb 10:267-274

36. Poller WC, Pieber M, Boehm-Sturm P, Ramberger E, Karampelas V, Möller K, Schleicher M, Wiekhorst F, Löwa N, Wagner S, Schnorr J, Taupitz M, Stangl K, Stangl V, Ludwig A (2018) Very small superparamagnetic iron oxide nanoparticles: long-term fate and metabolic processing in atherosclerotic mice. Nanomed Nanotechnol Biol Med 14:2575-2586

37. Poller WC, Ramberger E, Boehm-Sturm P, Mueller S, Möller K, Löwa N, Wiekhorst F, Wagner S, Taupitz M, Schellenberger E, Baumann G, Stangl K, Stangl V, Ludwig A (2016) Uptake of citratecoated iron oxide nanoparticles into atherosclerotic lesions in mice occurs via accelerated transcytosis through plaque endothelial cells. Nano Res 9:3437-3452

38. O'Halloran TV, Culotta VC (2000) Metallochaperones, an intracellular shuttle service for metal ions. J Biol Chem 275:25057-25060

39. Briley-Saebo K, Bjørnerud A, Grant D et al (2004) Hepatic cellular distribution and degradation of iron oxide nanoparticles following single intravenous injection in rats: implications for magnetic resonance imaging. Cell Tissue Res 316:315-323

40. Kwon HM, Sangiorgi G, Ritman EL, McKenna C, Holmes DR Jr, Schwartz RS, Lerman A (1998) Enhanced coronary vasa vasorum neovascularization in experimental hypercholesterolemia. J Clin Invest 101:1551-1556

41. Meding J, Urich M, Licha K, Reinhardt M, Misselwitz B, Fayad ZA, Weinmann HJ (2007) Magnetic resonance imaging of atherosclerosis by targeting extracellular matrix deposition with Gadofluorine M. Contrast Media Mol Imaging 2:120-129

42. Wiener E, Settles M, Weirich G, Schmidt C, Diederichs G (2011) The influence of collagen network integrity on the accumulation of gadolinium-based MR contrast agents in articular cartilage. RöFo Fortschritte Auf Dem Geb Röntgenstrahlen Bildgeb Verfahr 183:226232

43. Karangelis ED, Kanakis IP, Asimakopoulou A et al (2010) Glycosaminoglycans as key molecules in atherosclerosis: the role of versican and hyaluronan

44. Uca YO, Taupitz M (2020) Glycosaminoglycans as novel targets for in vivo contrast-enhanced magnetic resonance imaging of atherosclerosis. J Cardiol Cardiovasc Med 5:9

45. Lindahl U, Hook M (1978) Glycosaminoglycans and their binding to biological macromolecules. Annu Rev Biochem 47:385-417

46. McDonald RJ, McDonald JS, Kallmes DF et al (2015) Intracranial gadolinium deposition after contrast-enhanced MR imaging. Radiology 275:772-782

47. Iimuro $\mathrm{Y}$, Yamamoto M, Kohno H, Itakura J, Fujii H, Matsumoto Y (1994) Blockade of liver macrophages by gadolinium chloride reduces lethality in endotoxemic rats - analysis of mechanisms of lethality in endotoxemia. J Leukoc Biol 55:723-728

48. Weng T-I, Chen HJ, Lu C-W et al (2018) Exposure of macrophages to low-dose gadolinium-based contrast medium: impact on oxidative stress and cytokines production. Contrast Media Mol Imaging 2018:3535769

49. Reynolds JL, Joannides AJ, Skepper JN, McNair R, Schurgers LJ, Proudfoot D, Jahnen-Dechent W, Weissberg PL, Shanahan CM (2004) Human vascular smooth muscle cells undergo vesiclemediated calcification in response to changes in extracellular calcium and phosphate concentrations: a potential mechanism for accelerated vascular calcification in ESRD. J Am Soc Nephrol 15:2857-2867

50. Proudfoot D, Shanahan CM (2001) Biology of calcification in vascular cells: intima versus media. Herz 26:245-251 